\title{
Health Extension in New Mexico: An Academic Health Center and the Social Determinants of Disease
}

\author{
Artbur Kaufman, MD \\ Wayne Powell, MA \\ Charles Alfero, MA \\ Mario Pacheco, MD \\ Helene Silverblatt, $M D$ \\ Juliana Anastasoff, MS \\ Francisco Ronquillo, PA \\ Ken Lucero \\ Erin Corriveau, MD \\ Betsy Vanleit, PbD, OT \\ Dale Alverson, MD \\ Amy Scott, MD, MPA

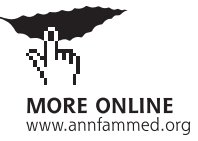

Conflicts of interest: none reported

CORRESPONDING AUTHOR

Arthur Kaufman, MD

HSC Office for Community Health

1 University of New Mexico

FPC 137 MSC09 5065

Albuquerque, NM 87131-0001

akaufman@salud.unm.edu

\begin{abstract}
The Agricultural Cooperative Extension Service model offers academic health centers methodologies for community engagement that can address the social determinants of disease. The University of New Mexico Health Sciences Center developed Health Extension Rural Offices (HEROs) as a vehicle for its model of health extension. Health extension agents are located in rural communities across the state and are supported by regional coordinators and the Office of the Vice President for Community Health at the Health Sciences Center. The role of agents is to work with different sectors of the community in identifying high-priority health needs and linking those needs with university resources in education, clinical service and research. Community needs, interventions, and outcomes are monitored by county health report cards. The Health Sciences Center is a large and varied resource, the breadth and accessibility of which are mostly unknown to communities. Community health needs vary, and agents are able to tap into an array of existing health center resources to address those needs. Agents serve a broader purpose beyond immediate, strictly medical needs by addressing underlying social determinants of disease, such as school retention, food insecurity, and local economic development. Developing local capacity to address local needs has become an overriding concern. Communitybased health extension agents can effectively bridge those needs with academic health center resources and extend those resources to address the underlying social determinants of disease.
\end{abstract}

Ann Fam Med 2010;8:73-81. doi:10.1370/afm.1077.

While medical care can prolong survival and improve prognosis after some serious diseases, more important for the bealth of the population as a whole are the social and economic conditions that make people ill and in need of medical care in the first place... Good bealth involves reducing levels of educational failure, reducing insecurity and unemployment and improving bousing standards.

Wilkinson and Marmot ${ }^{1}$

\section{INTRODUCTION}

$\mathrm{N}$ ew Mexico is a large, rural, multiethnic state with the second highest uninsured rate in the nation, 30 of its 33 counties federally are designated Health Profession Shortage Areas, and $60 \%$ of the population lives in rural or frontier communities with variable access to services. The University of New Mexico (UNM) Health Sciences Center (UNMHSC) surveyed rural community health leaders on how the UNMHSC might better serve their health needs. The results were sobering. Many viewed UNMHSC as the University of Albuquerque. Some complained that UNMHSC resources were fragmented, unknown, or inaccessible to most of the state; UNMHSC's interest in communities seemed limited to the duration of a grant or research project; and UNM infrequently acknowledged community assets, aims, or priorities. 
Leaders commented that UNMHSC's level of community engagement compared poorly with that of the state's land grant university-New Mexico State University (NMSU). NMSU, through its statewide Cooperative Extension Service, places extension agents in every county and in 5 tribal communities. Agents participate in local fairs and rodeos, sponsor the local 4-H clubs, and assist farmers, ranchers, and families in addressing daily work and home-life challenges. Educational programs that agents undertake usually arise in response to needs identified at the local level. ${ }^{2}$ In addition, agents are a direct link for the community to NMSU's specialty resources.

Social determinants of health and disease "are the conditions in which people live and work, and that affect their opportunities to lead healthy lives." 3 The Cooperative Extension Service works closely with the day-to-day, economic, nutritional, and agricultural infrastructure challenges to community well-being, whereas academic health centers focus on the more costly medical consequences of adverse social conditions. How could the Cooperative Extension Service model be adapted to academic health centers? Since its inception in 1914, the Cooperative Extension Service has disseminated knowledge from the land-grant universities to all communities ${ }^{4,5}$ and seemed to be a model of engagement that is transferable from the agricultural to the health sector.

\section{HEALTH EXTENSION PROGRAM}

The outcome of meetings with community leaders and NMSU's Cooperative Extension Service was the development of a statewide Health Extension Rural Office (HERO) program. Its mission is to improve community health and local capacity by linking community health priorities with UNMHSC resources. The HERO program is coordinated by the UNMHSC Office of the Vice President for Community Health $(\mathrm{OVPCH})$ and works through local HERO agents who live and work at the community level, as well as through HERO regional and tribal coordinators who provide regional linkage between the OVPCH and HERO agents.

The OVPCH was established to link UNMHSC resources with state health needs. It coordinates community health activities with the School of Medicine, Colleges of Nursing and Pharmacy, and UNMHSC hospitals. It is headed by a newly created position of Vice President for Community Health, which, along with vice presidents of clinical affairs, hospital operations, translational research, interdisciplinary research, and diversity, reports to the executive vice president for health sciences. Programs run by the OVPCH reflect state, county, and tribal priorities and support
HERO activities, such as telemedicine, behavioral health, oral health, statewide immunization, and communications. Associate vice presidents and their centers for Hispanic health, Native American health, and African-American health are charged with reducing health disparities, increasing educational attainment, improving access to care, and developing communityderived research and translational research linkages with their respective center's communities of interest.

\section{HERO Agents}

The HERO agents' primary role is defined in Table 1: they act as local resources for their communities while accessing resources of UNMHSC in all mission areas (education, service, research). They facilitate collaboration and capacity building among many community-based and community-serving organizations and agencies. Such facilitation involves different sectors of the community, including local health and educational systems, behavioral health collaboratives, county public health offices, Community Extension Service agents, community colleges, and school-based clinics. Agents invariably work with 5 important, community-based collaborators in each region: the county health planning councils, the area health education centers, the county cooperative extension agents, the public health clinics, and the local health clinicians and hospitals that have entered affiliation agreements with UNMHSC. Each group has intimate knowledge of different aspects of the community, and the HERO agent learns from, partners with, and fosters links between them.

\section{HERO Regional Coordinators}

Because of New Mexico's size, it was necessary to provide regional support to HERO agents through 3 regional coordinators: 1 based in Las Cruces near the US/Mexican border, housed with an Area Health Education Center (AHEC), and focused on southern New Mexico communities; 1 based at the UNM-Taos

\section{Table 1. HERO Agent's Role Within the Community}

Live in community

Link local community health needs with UNMHSC resources Mobilize participation of different sectors of the community Improve local health services and systems

Encourage youth to finish school, enter health careers

Recruit and retain local health workforce

Bring latest research, evidence-based health care practices to community

Strengthen community capacity to address local health problems

HERO $=$ Health Extension Rural Office of the University of New Mexico Health Sciences Center. 


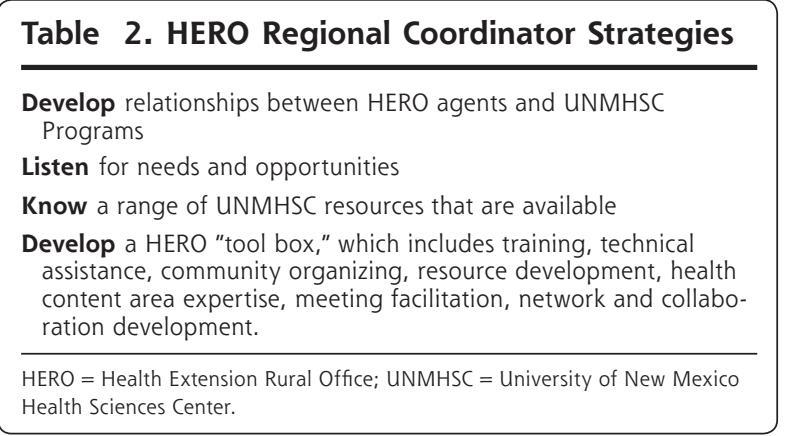

branch campus and focused on northern New Mexico communities; and 1 based at the Indian Pueblo Cultural Center in Albuquerque and focused on tribal communities throughout the state.

Because community health priorities differ by county and ethnic group, HERO regional coordinators have devised an array of strategies to link communities and HERO agents with the OVPCH (Table 2). In addition, they help build local infrastructure and provide technical assistance in the field.

\section{UNMHSC Office for Community Health}

The OVPCH is in constant communication with HERO regional coordinators and local HERO agents around the state. Each time coordinators visit a community, they complete a short, electronic community SOAP (subjective, objective, assessment, and plan) note describing problem priorities, interventions, progress made, and plan for follow-up. Every 2 weeks, there is a HERO organizational team meeting, attended by the vice president, associate director, staff, and regional coordinators of the OVPCH. Community "rounds" are conducted at each meeting.

Monthly, there is a UNMHSC-wide community health meeting, where internal partners from all branches of the Health Sciences Center (eg, Information Technology, Mental Health, Public Health, Area Health Education Center, School of Medicine, College of Nursing, College of Pharmacy, Medical Library, Allied Health programs, Oral Health, Office of Diversity, Centers for Native American Health, Hispanic Health, and African-American Health) hear updates from HERO coordinators and share other resources that agents and coordinators take back to the community.

\section{Funding for HEROs Program}

Sustainability of the HEROs program has been a concern since its inception In light of community calls for long-term commitment to them by UNMHSC, the OVPCH has sought a stable funding stream emphasizing hard, state dollars and reallocation of existing resources and positions toward the effort. The Office of the Executive Vice President has allocated to the OVPCH state dollars for partial support of staff and regional HERO coordinators. The 5 community hospitals affiliated with UNMHSC are either funding new agents or allocating HERO agent tasks to existing staff to serve their catchment area. Portions of grants from the J. F. Maddox Foundation, the Regional McCune Foundation, and a Health Resources and Services Administration-funded UNMHSC practice-based research network partially support the salaries of the HERO agents and regional coordinators.

Much of local the HERO agents' efforts are not funded externally, however, but require a reallocation of time within existing, full-time jobs that range from a chief executive officer of a community health center, to a director of a social service department at an Indian Health Service Hospital, a director of a regional Area Health Education Center, a director of a health professions school on a rural branch campus, and a chief executive officer of a community hospital. Local communities provide office space and telephone service. The HERO agents' role is sustained because of the technical assistance they provide and valuable resources they can bring from UNMHSC to improve their community's health and local capacity development.

Despite resource constraints, the HERO program continues to grow. Although increased funding would foster greater program stability, more rapid expansion, and greater health impact, the lack of substantial extramural funding has generated creative approaches to funding at the local level, and such local investment of time and resources is an important element in sustainability.

\section{HERO ACTIVITIES: BUILDING TRUST, BUILDING LOCAL CAPACITY}

Academic health centers build trust with communities by addressing their urgent health concerns, such as finding a clinician or assuring access to emergency care after hours. If these needs are attended to, trust is increased and the underlying social determinants of health and chronic disease can be addressed, such as educational attainment, food security, or economic development. ${ }^{5-8}$ Communities are cognizant of these determinants but are not aware that academic health centers can play a role in addressing them. The HERO agent raises community awareness of this academic role. Communities have their own personalities, interests and needs to which HERO agents must adapt. Two communities from different parts of the state exemplify the similarities and difference in an initial HERO agent's activities. 


\section{Silver City, New Mexico}

The local volunteer HERO agent is also the head of Hidalgo Medical Services, a community health center serving several frontier counties in the southwest corner of the state. The community's health alliance identified high-priority health needs, developed interventions, and sought resources to address those needs. Health discussions were intermingled with concerns about social stressors of job insecurity and a weakened economy after the local copper mines closed.

The Silver City community had a list of requests:

1. Help recruit and train local health professionals_-an economic development effort.

2. Create a care model featuring one-stop shopping for medical, dental, behavioral, and social services - keeping health care dollars local, reducing cost of travel, lost work.

3. Address high rates of diabetes in Hispanic population-improving nutrition, decreasing obesity, controlling diabetes.

4. Retain pharmacy services since the community lost its only pharmacist-keeping open a vital business.

HERO responded in the following manner:

1. Hidalgo Medical Services and UNMHSC partnered in attracting health professionals to the area by offering free housing in Silver City to UNMHSC residents in family medicine, pediatrics, psychiatry, and dentistry and to physician assistants and medical students during their rural rotation. As a result, health professionals from each of those fields now have been recruited to Hidalgo Medical Services.

2. The OVPCH worked with Hidalgo Medical Services to develop the health commons, a concept that expands the patient-centered medical home by integrating in a single clinical center medical, behavioral, dental, and social services with community health worker outreach and local economic development. ${ }^{9}$ More community members now receive services locally, and the commons model is being adopted in 5 other communities in the state.

3. UNMHSC researchers helped Hidalgo Medical Services with a Center for Disease Control Reach 2010 grant to create La Vida, a program in which community health workers offer culturally appropriate assistance to Hispanic patients with diabetes to learn how to shop at local groceries and manage their disease at home. The outcome was a significant drop in participants' $\mathrm{HbA}_{1 \mathrm{C}}$ levels

4. UNMHSC College of Pharmacy helped revise New Mexico State Board of Pharmacy regulations to permit pharmacists in larger towns to use a telepharmacy service to supervise local pharmacy technicians in rural and frontier counties. Initiated by the local HERO agent, telepharmacy will permit the local phar- macy to remain open, which is a health and economic benefit to the community.

\section{Crownpoint, New Mexico}

The Crownpoint Indian Health Service (IHS) Hospital serves the Eastern Navajo Reservation inhabited by 27,000 individuals. The hospital administrator is the HERO agent working to integrate resources of the local Indian hospital, Community Extension Service office, and local Navajo Technical College. The Crownpoint community faced a variety of challenges. Turnover of their hospital staff was high, recruiting health care professionals was increasingly difficult, lack of cultural awareness by non-Native health care professionals reduced care quality, and the hospital had closed temporarily because its laboratory failed inspection. Addressing these problems would also address 2 underlying social determinants of Native Americans on reservations-low graduation rates from school and low employment. With the IHS health care system being one of the reservation's largest employers, the community and the service unit wanted to focus on attracting local youth to health careers and retaining them in their home communities.

The Crownpoint community had the following requests:

1. Improve the quality of the Indian hospital laboratory-keep the hospital open.

2. "Grow our own" health professionals programincrease school retention.

HERO responded in the following manner:

1. The UNM Department of Pathology sent laboratory science specialists to consult with the Crownpoint Indian Hospital. In addition, they offered to train local students to become licensed laboratory technicians via distance learning to the local tribal college

2. UNMHSC and NMSU Community Extension Service held an all-day health careers summit for Eastern Navajo middle school students. The intent was to expose local youth to opportunities beyond the boundaries of the reservation. Interested students were assigned mentors to support their interests, provide guidance, and encourage school completion.

\section{HERO THEMES: SOCIAL DETERMINANTS THAT EMERGE ACROSS COMMUNITIES Economic Development and the Rural Health Workforce}

A rural health workforce is needed not only to address health ${ }^{10}$ but to grow the local economy. Each physician practicing in a rural community generates approximately $\$ 1$ million a year for the community, hires on 
the average of 18 people directly or indirectly, and helps the community attract businesses and retirees. ${ }^{11}$

While community colleges and branch campuses have been working on pipeline programs at the certificate and associate degree level for some time, until HERO started up this year, the pipeline inlet for rural communities to more advanced health sciences education was basically limited to recruitment efforts, because it is impossible to hear and address rural community needs from Albuquerque (HERO coordinator).

Academic health centers have failed to produce the workforce needed for rural communities, both by specialty and geography. They draw learners from rural communities and usually train them on an urban campus. This system is problematic because once local youth leave home to attain their health career goals, they rarely return. Others in rural communities, interested in furthering their health careers, never get a chance because they cannot travel to urban colleges and abandon their family obligations.

One solution promoted by the HERO program involves better use of distance learning and health information technology available through the UNMHSC library's distance services and evidencebased, online resources. Distance education that uses videoconferencing and online courses affords rural students an education in their home community. The Crownpoint plan to use distance learning to train laboratory technicians at the local tribal college is a case in point.

\section{Educational Attainment and Community Health} New Mexico has a high secondary school dropout rate, and the problem is especially acute for Native American and Hispanic students. ${ }^{12}$ Investment in increasing school achievement has major health benefits for students, their families, and communities. Educational attainment is correlated with higher earning power, greater choices in life, and lower health risk behaviors and chronic disease rates. ${ }^{1}$ With the health sector of the economy continuing to grow, accelerated by an aging population, encouraging youth's interest in health careers increases their likelihood of job security in the future.

In response, HERO agents have worked with communities to expand health career pathways for youth. In both the Silver City and Crownpoint examples, emphasis has been placed on exposing youth to health careers, and providing opportunities for health professional students to gain experience working in rural hospitals and clinics. The HERO agent in Las Vegas, New Mexico, is an Area Health Education Center director who also sits on the local school board. The community, in collaboration with the HERO regional coordinator and agent, is mapping their existing health career pipeline activities and developing strategies to improve the strength and continuity of the pipeline for local youth, starting from early childhood and including such programs as Head Start and 4-H Clubs.

\section{Access to Social Support: Community Health Workers and the Patient-Centered Medical Home}

The OVPCH and HERO agents have helped train and deploy community health workers as an important component and extension of case management services within primary care clinics and patient-centered medical homes. As community-based rather than clinicbased employees, community health workers have been far more successful than clinic-based case managers in maintaining sustained contact with patients with complex medical, social, and behavioral conditions who are high users of emergency departments and preventable hospitalizations. These workers link these patients with an array of social support services, including food banks, emergency utilities support, housing options, literacy classes, transportation, and support groups, thereby better coordinating care and sharply reducing the cost of these patients to the health care system. By using an already established web of local communication and services, community health workers help primary care clinicians access a broader set of services for patients and their families beyond what is available within the patient-centered medical home.

There is deserved enthusiasm about the collaboration between the 3 primary care specialties in conceptualizing and jointly promoting the expanded quality, efficiency, and impact on health of primary care services through the patient-centered medical home..$^{13}$ Yet, while the Institute of Medicine's definition of primary care includes "practicing in the context of family and community," community remains the most neglected component of primary care. The HERO agents and regional coordinators address this component by addressing the social determinants of disease.

Finally, informing public policy and developing a sustainable resource to support the community health workers employed within various systems have been priorities of the OVPCH. Developing, implementing, and testing models of field case management by community health workers have become vital components of a financing strategy for support of the community health workers in the future. Assessing employer requirements, developing training curricula, and in some areas of service, determining the credential or certification requirements for community health workers grow from the field experiences of the HERO agents and the various partners using the community health workers' expertise 
to reduce health disparities and improve efficiency and effectiveness of health care programs.

\section{Health and Food Security}

Community health priorities include access to highquality food. The state's Roadrunner Food Bank approached the HERO program to create food pantries (distribution sites) in areas of food insecurity where Roadrunner wanted to deliver food, but where no local church, school, or civic organization had volunteered to set up a pantry for its distribution. To increase the appeal to local communities of sponsoring a pantry, a local HERO agent in the southeastern town of Roswell supported local frontier community efforts in establishing pantries. She did this by adding other components to food distribution - health services and health screening (eg, blood pressure checks, blood glucose measures, dental screening) provided by interdisciplinary health professions students. Her efforts led to the establishment of 5 new pantries. Future project aims address the social determinants of poor nutrition and obesity by integrating social services at the sites, expanding service-learning opportunities for health science students studying at the local community college, creating mentoring experiences for rural youth, increasing local capacity to sustain programs that increase access to and production of health-promoting diets, and increasing nutritional literacy for community members to combat obesity and other chronic conditions.

\section{HEROS AND COMMUNITY-BASED RESEARCH}

UNMHSC research priorities do not always match community health priorities (Table 3 ). The HERO program helps bridge this divide. HERO agents are working to strengthen UNMHSC research endeavors' response to community-directed targets through its practice-based research network. ${ }^{14}$ The HERO model not only offers a channel for rapid dissemination of discoveries and best practices from universities to communities, but offers a bidirectional benefit by feeding high-priority community questions and needs back to researchers at the university. These community priorities (eg, substance abuse, violence) invariably call on the investigator to address the social determinants of disease.

\section{MONITORING COMMUNITY HEALTH AND OUTCOMES TO DATE}

To strengthen awareness of community strengths and needs, the OVPCH has collaborated with the New Mexico Department of Health in developing county health report cards (Supplemental Figure 1, available

\section{Table 3. 2007 Top Health Priorities From 31 County and 6 Tribal Health Councils Compared With UNMHSC Research Priorities}

\begin{tabular}{ll}
$\begin{array}{l}\text { County Health } \\
\text { Councils' Priorities }\end{array}$ & $\begin{array}{l}\text { UNMHSC Research Priorities } \\
\text { (Signature Programs) }\end{array}$ \\
\hline Substance abuse & Cancer \\
Teen pregnancy & Cardiovascular and metabolic diseases \\
Obesity & Brain and behavior \\
Access to care & Child health \\
Violence & Infectious disease and immunity \\
Diabetes & Environmental health
\end{tabular}

UNMHSC $=$ University of New Mexico Health Science Center.

at available at: http://www.annfammed.org/cgi/ content/full/8/1/73/DC1), which allow input and tracking by agents, communities, agencies, and the UNMHSC. The report cards provide data on a range of important measures, including leading causes of morbidity and mortality, health workforce status, community planning priorities, and existing UNMHSC education, service, and research programs. HERO agents can use the report cards to track the responsiveness and effectiveness of UNMHSC programs in addressing community health needs. The report cards also help bridge community services, which tend to exist in medicine and public health silos, fostering needed complementary resource allocation to high-priority community needs. ${ }^{15}$

Two years have elapsed since the inception of the HERO program. Although it is premature for HERO interventions to greatly affect community health outcomes, there has been a notable attitudinal shift at UNMHSC regarding forming alliances with community partners, sustaining presence in and relationships with communities, and incorporating social determinants as legitimate areas for investigation, education, and clinical service. This year, the leadership-vice presidents and deans of UNMHSC - agreed to a new, comprehensive strategic goal for all components of the Health Science Center: "Working with community partners, UNMHSC will help New Mexico make more progress in health than any other state by $2020 . "$ This strategic goal is to be incorporated into the performance plan of each college, each department, each division, and each faculty member.

To support the new strategic goal in 2009, UNMHSC formed the New Mexico Partnership for the Reduction of Health Disparities, comanaged by UNMHSC and the New Mexico Department of Health. Personnel and offices will be shared between the 2 entities, with the partnership focusing on identifying counties and communities with major health disparities and forming with those communities an 
intervention plan whose outcomes will be monitored. As a component of the partnership, UNMHSC's HERO agents are now collaborating with the Department of Health's county health councils at the local level in tracking health disparities and initiating new interventions.

The benefits emerging from this type of collaboration are illustrated by data from the Department of Health showing that these same counties have the highest rates of childhood asthma and hospitalization for asthma in the state, as well as high rates of childhood obesity, second-hand smoke exposure, and environmental pollution from the local oil and gas industry. ${ }^{16}$ Of note, deteriorating housing was identified as a health priority by the Lea County Health Council in 1 of the 3 southeastern counties. Partnership members are now working with HERO agents and health council members in that county, mounting a community education campaign targeting asthma to reduce exposures and improve self-care and management by school nurses and health care clinicians.

\section{MAJOR OBSTACLES, SOURCES OF RESISTANCE}

Even though the HEROs Program has received praise and institutional support, it faces 5 recurrent obstacles to broadening its appeal and diffusion of its approaches in the community and within UNMHSC.

1. Lack of sufficient resources. An underresourced but highly valued program in the eyes of a community can be sustained by extraordinary community effort, but the risk is that in the long run, the program can cannibalize an already-stretched health workforce and dollar resources.

2. Unfamiliarity of the institution with social determinants. Many faculty are uncomfortable intervening in areas in which they are neither leaders nor well prepared. Social determinants seem to them more appropriately addressed by other sectors of the community and other systems of care, such as public health, social services, the school system, or policy makers.

3. Discomfort with community anger. Students and faculty in the health professions are usually ill-prepared for the anger expressed by members of communities struggling with complex economic, social, and educational issues, some of which are aimed at past grievances against the institution the students and faculty represent.

4. Conflict between UNMHSC strengths and community needs. The academic health center tends to view community health needs through the prism of the health center's existing interests and strengths in research, clinical specialty services, and educational focus. These areas, however, are often discordant with community needs and priorities.

5. Lack of campus awareness of critical community health problems. The academic health center community is made aware on a daily basis of crisis problems on campus - such as the hospital beds being filled, the emergency department backing up, and ambulances being diverted. The health center community is not equally cognizant of important health crises in the communities it serves-problems they could help address if links with the community were strengthened and internal communication about community needs was robust.

\section{OTHER MODELS}

There is a precedent for collaboration between academic health centers and a community extension service. At the University of Kentucky, the Cooperative Extension Service of the College of Agriculture and the College of Public Health are located on the same campus. An example of collaboration is illustrated by the Southeast Center for Agricultural Health and Injury Prevention being housed in the College of Public Health. It addresses jointly such issues as farmer suicide prevention and tractor rollover protection. A collaborative relationship having been established, the College of Public Health and the College of Agriculture then partnered on the Health Education through Extension Leadership (HEEL) project. Unlike New Mexico's HERO program, which focuses on community-derived health priorities in all university mission areas (education, clinical service, and research), the HEEL project collaboration focuses on reducing Kentucky's chronic disease preventable risk factors. Further, the role of health extension in this model is built upon similarities between community health education goals from both colleges. ${ }^{17}$

In another example, the University of Wisconsin offers a model of health extension focused on scholarship. ${ }^{18}$ Its Health Extension Program grew as a component of its Institute for Clinical Translational Research. Like New Mexico's program, it has hired 3 regional, community-based health extension coordinators who have links with their area health education center system and are responding to priority setting by local, representative councils. Unlike New Mexico, however, Wisconsin's program focus and representative council advice are limited to research.

Grumbach and Mold in a recent commentary called for a broad application of the community extension service model to primary care through health extension. ${ }^{19}$ It cites the Oklahoma Physicians Resource/Research Network (OKPRN), led by a collaborative effort 
between the Oklahoma Academy of Family Physicians and the University of Oklahoma Department of Family and Preventive Medicine, which trains and deploys a cadre of practice enhancement assistants who have roles analogous to those of agriculture extension agents. Whereas the New Mexico program focuses broadly on various aspects of community health, the Oklahoma program focuses on primary care practice-with their assistants helping more than 200 clinicians in more than 100 sites improve quality of care. Their program is linked to their practice-based research network.

\section{LESSONS LEARNED: IMPLICATIONS OF HEALTH EXTENSION FOR ACADEMIC HEALTH CENTERS}

1. Community resiliency. Communities are resilient, responsive, and able to increase their effectiveness in dealing with local problems if given the opportunity to access the educational, service, and research resources of the academic health center.

2. Trust. Trusting relationships with communities require a long-term commitment and grow from receptive, positive consideration and action by the academic health center in response to community requests, priorities and assets.

3. Broadening academic health center offerings. Academic health centers tend to offer communities single-disease focused and revenue-driven services reinforced by the specialty orientation of departments and divisions. As a result, the socioeconomic root causes of disease are left unaddressed. The HERO model, adapted from the agricultural Community Extension Service, can expand the range of academic health center services to communities.

4. Central role of health extension agents in community health. The HERO program is well-suited to address health in the context of social determinants, largely because its hub is the community itself. HERO agents can provide direct, technical assistance to communities and help communities navigate the complex, resource-rich environment of the academic health center, activating comprehensive interventions to improve community health.

5. Community role in integrating academic health center resources. The HERO program has shown that to address high-priority community health needs, the resources of the academic health center existing in silos can be integrated productively at the community level and linked to resources in other sectors of the community, including education, food distribution, economic development, and policy development.

6. Community role in determining health priorities. Agents interact in and with communities and the
UNMHSC in a manner that is culturally, linguistically, and regionally relevant to community groups. In the end, HERO activities are guided by the communities' priorities with the intent to support and grow local capacity that becomes self-sustaining and healthy in the broadest sense of the word.

To read or post commentaries in response to this article, see it online at http://www.annfammed.org/cgi/content/full/8/1/73.

Key words: Health extension; social determinants; academic health center

Submitted July 21, 2009; submitted, revised, October 13, 2009; accepted October 30, 2009.

Authors' affiliations: Office for Community Health, Health Sciences Center, University of New Mexico, Albuquerque, New Mexico (Kaufman, Powell, Pacheco, Silverblatt, Anastasoff, Lucero, Corriveau, Vanleit, Alverson, Scott); Department of Family and Community Medicine, School of Medicine, University of New Mexico, Albuquerque, New Mexico (Kaufman, Pacheco, Corriveau); Hidalgo Medical Services, Lordsburg, New Mexico (Alfero); Department of Psychiatry, School of Medicine, University of New Mexico, Albuquerque, New Mexico (Silverblatt); Robert Wood Johnson Foundation Center for Health Policy, University of New Mexico, Albuquerque, New Mexico (Lucero); Indian Pueblo Cultural Center, Albuquerque, New Mexico (Lucero); Occupational Therapy Program, Department of Pediatrics, School of Medicine, University of New Mexico, Albuquerque, New Mexico (Vanleit); Center for Telehealth and Cybermedicine, Health Sciences Center, University of New Mexico, Albuquerque, New Mexico (Alverson); Department of Pediatrics, School of Medicine, University of New Mexico, Albuquerque, New Mexico (Scott)

Funding support: This research was supported by the W.K. Kellogg Foundation Community Voices.

Acknowledgments: We thank Paul Gutierrez and Roberta Rios for enriching our understanding of Cooperative Extension; Carolina Nkouaga for providing technical assistance to the HERO agents; Elaine Luna, Christina Campos, Jane Batson, Mary Ann O'Neal, Deborah Weiss and Khadijah Bottom for pioneering the new role of Health Extension Agent; Paul Akmajian for creating a statewide HERO communications network; Kate O'Neill, James Gilroy, Benjamin Jacquez, Robert Reid and Steve McCreery for facilitating development of HERO agents' role in local communities; Alfredo Vigil and Karen Armitage of the Department of Health for their involvement in our health disparities reduction efforts; and Paul Roth, UNMHSC Executive Vice President for providing administrative and financial support for the growth of the HERO program.

\section{References}

1. Wilkinson RG, Marmot MG. Social Determinants of Health: The Solid Facts. World Health Organization. Regional Office for Europe, WHO Health Cities Project, WHO International Centre for Health and Society. 2nd ed. Geneva: World Health Organization; 2003.

2. Rasmussen WD. Taking the University to the People: Seventy-five Years of Cooperative Extension. West Lafayette, IN: Purdue University Press; 2002.

3. Labonté R, Schrecker T. Globalization and social determinants of health: Introduction and methodological background (part 1 of 3). Global Health. 2007;3:5. http://www.globalizationandhealth. com/content/3/1/5. 
4. Rogers EM. Diffusion of Innovations. New York, NY: The Free Press; 1995.

5. Sanders HC, ed. The Cooperative Extension Service. Englewood Cliffs, NJ: Prentice-Hall, Inc; 1966.

6. Donaldson MA, Yordy KD, Lohr KN, Vanselow NA, eds. Primary Care: America's Health in a New Era. Washington, DC: National Academy Press; 1996.

7. Berkman LF, Syme SL. Social networks, host resistance, and mortality: a nine-year follow-up study of Alameda County residents. Am J Epidemiol. 1979;109(2):186-204.

8. Brunner EJ, Hemingway H, Walker BR, et al. Adrenocortical, auto nomic, and inflammatory causes of the metabolic syndrome: nested case-control study. Circulation. 2002;106(21):2659-2665.

9. Kaufman A, Derksen D, Alfero C, et al. The Health Commons and care of New Mexico's uninsured. Ann Fam Med. 2006;4(Suppl 1): S22-S27, discussion S58-S60.

10. Goodman DC. Linking Workforce Policy to Health Care Reform. Invited Testimony. United States Senate Committee on Finance, hearing on "Workforce Issues in Health Care Reform: Assessing the Present and Preparing for the Future". March 12, 2009.

11. Doekson GA, Johnson T, Biard-Holmes $D$, et al. A health sector is critical to community economic development. J Rural Health. 1998;14(1):66-72.

12. Opdycke S, Miringoff M-S. The Social Health of the States. Poughkeepsie, NY: Vassar College, Institute for Innovations in Social Policy; 2008
13. Rogers JC. The patient-centered medical home movement-promise and peril for family medicine. J Am Board Fam Med. 2008;21(5): 370-374.

14. Sinclair-Lian N, Rhyne RL, Alexander SH, Williams RL. Practicebased research network membership is associated with retention of clinicians in underserved communities: a Research Involving Outpatient Settings Network (RIOS Net) study. J Am Board Fam Med. 2008;21(4):353-355.

15. Lurie $N$, Fremont $A$. Building bridges between medical care and public health. JAMA. 2009;302(1):84-86.

16. Whorton B. High child asthma rates in southeastern New Mexico. New Mexico Epidemiol. 2009; 4:1-4.

17. Scutchfield FD, Harris TT, Tanner B, et al. Academic health centers and Cooperative Extension service: a model for a working partnership. J of Extension. 2007;45(1)1 FEA5.

18. Frey J, Dunham NC, Cohn T. Matchmaker, matchmaker: health extension program connects Wisconsin researchers. DFN Showcase. Fall 2009. http://fammed.wisc.edu/our-department/newsletter/ fall-2008/health.

19. Grumbach K, Mold JW. A health care cooperative extension service: transforming primary care and community health. JAMA. 2009;301(24):2589-2591. 